This is a peer-reviewed, accepted author manuscript of the following article: Satayeva, A. R., Howell, C. A., Korobeinyk, A. V., Jandosov, J., Inglezakis, V. J., Mansurov, Z. A., \& Mikhalovsky, S. V. (2018). Investigation of rice husk derived activated carbon for removal of nitrate contamination from water. Science of the Total Environment, 630, 1237-1245.

https://doi.org/10.1016/j.scitotenv.2018.02.329

\title{
Investigation of rice husk derived activated carbon for removal of nitrate contamination from water
}

\author{
Aliya R. Satayeva ${ }^{1}$, Carol A. Howell ${ }^{2}$, Alina V. Korobeinyk ${ }^{1,4}$, Jakpar Jandosov ${ }^{3}$, Vassilis J. \\ Inglezakis ${ }^{1}$, Zulkhair A. Mansurov ${ }^{3}$ and Sergey V. Mikhalovsky ${ }^{2, *}$ \\ ${ }^{1}$ Environmental Science \& Technology Group (ESTg), Chemical Engineering Department, School of \\ Engineering, Nazarbayev University, Astana, Kazakhstan \\ ${ }^{2}$ School of Pharmacy and Biomolecular Sciences, University of Brighton, UK \\ ${ }^{3}$ Institute of Combustion Problems, Almaty, Kazakhstan \\ ${ }^{4}$ O.O. Chuiko Institute of Surface Chemistry of NAS of Ukraine, Kyiv, Ukraine \\ *sergeymikhalovsky@gmail.com
}

\begin{abstract}
Development of porous carbons with high specific surface area (more than $1200 \mathrm{~m} \mathrm{~g}^{-1}$ ) targeted at nitrate removal from aqueous solutions is investigated by chemical activation of carbonized rice husk. Potassium carbonate is used as activating and desilicating agent. The effect of post-synthetic treatment by gas phase ammoxidation with ozone/ammonia or oxidation with concentrated nitric acid followed by nitrification with urea on main physicochemical properties and on the effectiveness of the activated carbons in nitrate removal is compared with those determined for a pristine activated carbonized rice husk sample. The two-fold enhancement of nitrate removal by the urea-modified activated carbon in comparison with pristine and ammoxidated sample is in direct correlation with the development of surface basic groups.
\end{abstract}

\section{Highlights:}

- Carbonized rice husk was activated yielding activated carbons with high surface area;

- Activated carbons (AC) were nitrified through ammoxidation or modification with urea;

- The nitrified AC surface basicity act as adsorption sites towards nitrate ions.

Keywords: biomass, rice husk carbonization, activated carbon, surface modification, nitrogen functionalization, nitrate ions adsorption.

\section{Introduction}

Nitrate is a potentially hazardous ion that is naturally present in groundwater. In addition, municipal, agricultural and industrial wastewater seepage enhance nitrate groundwater contamination. Water pollution due to excessive discharge of nitrate has become a significant environmental problem worldwide [1, 2]. The effect of nitrate on human health is described as primary toxicity [3]. Excess nitrate in drinking water may cause severe health problems such as infant cyanosis syndrome ("blue baby syndrome") due to methemoglobinemia [4, 5], central nervous system birth defect [6], and lead to possible formation of nitrosamines, which can cause various types of human cancer and other diseases [7-10]. An excess level of nitrate in groundwater can lead to eutrophication (harmful algae bloom, fish hypoxia and toxin production) [11].

The water denitrification is a complex and expensive process considering the solubility and stability of nitrate ion as well as its low adsorption affinity [12]. Current denitrification technologies include biologically-assisted [13] and physicochemical treatments. Biological methods require a large-scale installation and have slow ion removal kinetics. As for physicochemical methods, adsorption on activated carbon (AC) and ion-exchange resins were recognised as most effective for drinking water denitrification $[14,15]$. However commercial activated carbons and synthetic resins are costly and the quest for other adsorbing materials has continued. Recently, biomass, as a renewable source, has attracted attention for the preparation of porous carbons [16]. Traditionally activated carbons have been produced from agricultural waste products such as coconut shells, hazelnuts, cherry stones or apricot kernels which has kept production costs to a minimum [17-23]. Nevertheless, the literature on the nitrate uptake by ACs developed from 
agricultural waste is quite poor [24] and only few studies have reported the adsorption of nitrates from water using such ACs (See Supplementary information, SI, Table S1). Rice husk (RH), as an abundant by-product of rice milling industry, with low combustion value and potential damage to the environment, brings the issue of its sustainable utilization to the research hotspot [25-28]. Rice husk is composed of lignin, cellulose and $\mathrm{SiO}_{2}$, hence it can be considered as a natural organic-inorganic composite material [29]. Carbonization/activation of rice husk in inert atmosphere yields highly porous carbons with large specific surface area [30, 31]. Recently, porous carbons prepared from rice husk attracted attention in the field of energy storage [32], solar technology [16] and environmental protection [33]. Further research has been directed towards post-carbonization modification methods such as acid treatment [34] and introduction of positively charged basic functional groups $[35,36]$ that have capacity for removing oxyanions such as nitrate.

In 2017 Kazakhstan (KZ) produced 291,000 metric tons of rice, 20\% of which is RH [37]. The commercial value of $\mathrm{RH}$ does not exceed $£ 60$ per metric ton, and in fact most $\mathrm{KZ}$ rice producers offer it for free since it reduces their costs of waste disposal; therefore, one of the research objectives has been to investigate the possibility of producing novel porous carbons from locally available rice husk biomass.

In this work, rice husk was carbonized to produce carbonized rice husk (denoted as CRH). CRH was further subjected to potassium carbonate etching in order to desilicate the initial carbonized material and prepare a porous carbon (denoted as CRH-I). At the next step, CRH-I was nitrified via ammoxidation or modification with urea (samples denoted as CRH-II and CRH-III, correspondingly). All three samples of porous carbons (CRH-I, CRH-II and CRH-III) have large specific surface area and well developed porosity, and CRH-III also demonstrated elevated anion adsorption capacity.

\section{Experimental}

\subsection{Preparation of activated carbons}

AC samples were obtained from rice husk collected in the Bakanas Village, Balkhash District of Almaty Region via a procedure described elsewhere [38, 39]. Briefly, the RH material was initially washed and air dried at $105^{\circ} \mathrm{C}$ for $24 \mathrm{~h}$ in an oven and then pyrolyzed in air at $475{ }^{\circ} \mathrm{C}$, in a spherical rotary steel reactor (SI, Fig. S1) for 30 min to yield $41 \mathrm{wt} \%$ of carbonized rice husk $(\mathrm{CRH})$.

For the chemical alkaline activation and simultaneous removal of silica from the carbonized rice husk, a sample of $175 \mathrm{~g}$ of $\mathrm{CRH}$ was impregnated in solution of potassium carbonate $\left(\mathrm{K}_{2} \mathrm{CO}_{3}\right)$ for $24 \mathrm{~h}$, in order to facilitate the access of the alkaline inside the carbonized particles. The impregnation ratio of 1:4 (g CRH / $\mathrm{g} \mathrm{K}_{2} \mathrm{CO}_{3}$ ) was used producing the sample $\mathrm{CRH}-\mathrm{K}_{2} \mathrm{CO}_{3}$. After impregnation the sample was pyrolyzed in a cylindrical steel reactor placed inside a vertical electric furnace at $475{ }^{\circ} \mathrm{C}$ (SI, Fig. S2) and activated at $950{ }^{\circ} \mathrm{C}$ for 1 hour in an inert atmosphere of argon. The resulting material was washed with copious amount of distilled water until neutral $\mathrm{pH}$, to achieve a complete removal of potassium silicate from the carbonized sample, and then air dried overnight at $110^{\circ} \mathrm{C}$. The weight of the obtained AC sample CRH-I was $55.4 \mathrm{~g}$ giving a yield of $31.7 \mathrm{wt} \%$. CRH-I was further surface functionalized by two different routes, route 1 via mild ammoxidation yielding carbon CRH-II or route 2 in the two-step procedure yielding carbon CRH-III as shown in Fig. 1.

Mild-temperature ammoxidation of CRH-I was carried out in a quartz tube reactor inside a horizontal electric furnace (SI, Fig. S3). The sample placed in a quartz boat was oxidized with ozone/air mixture at 130 ${ }^{\circ} \mathrm{C}$ for $24 \mathrm{~h}$ (at gas flow rate of $1 \mathrm{~L} / \mathrm{min}$ ), immediately followed by the reaction with gaseous ammonia in the same reactor (one-pot synthesis) at $350{ }^{\circ} \mathrm{C}$ for $5 \mathrm{~h}$ (at gas flow rate of $5-6 \mathrm{~mL} / \mathrm{min}$ ) to yield $93.1 \mathrm{wt} \%$ of the ammoxidized product CRH-II. 


\section{Scheme of Rice Husk Conversion into Activated Carbon}

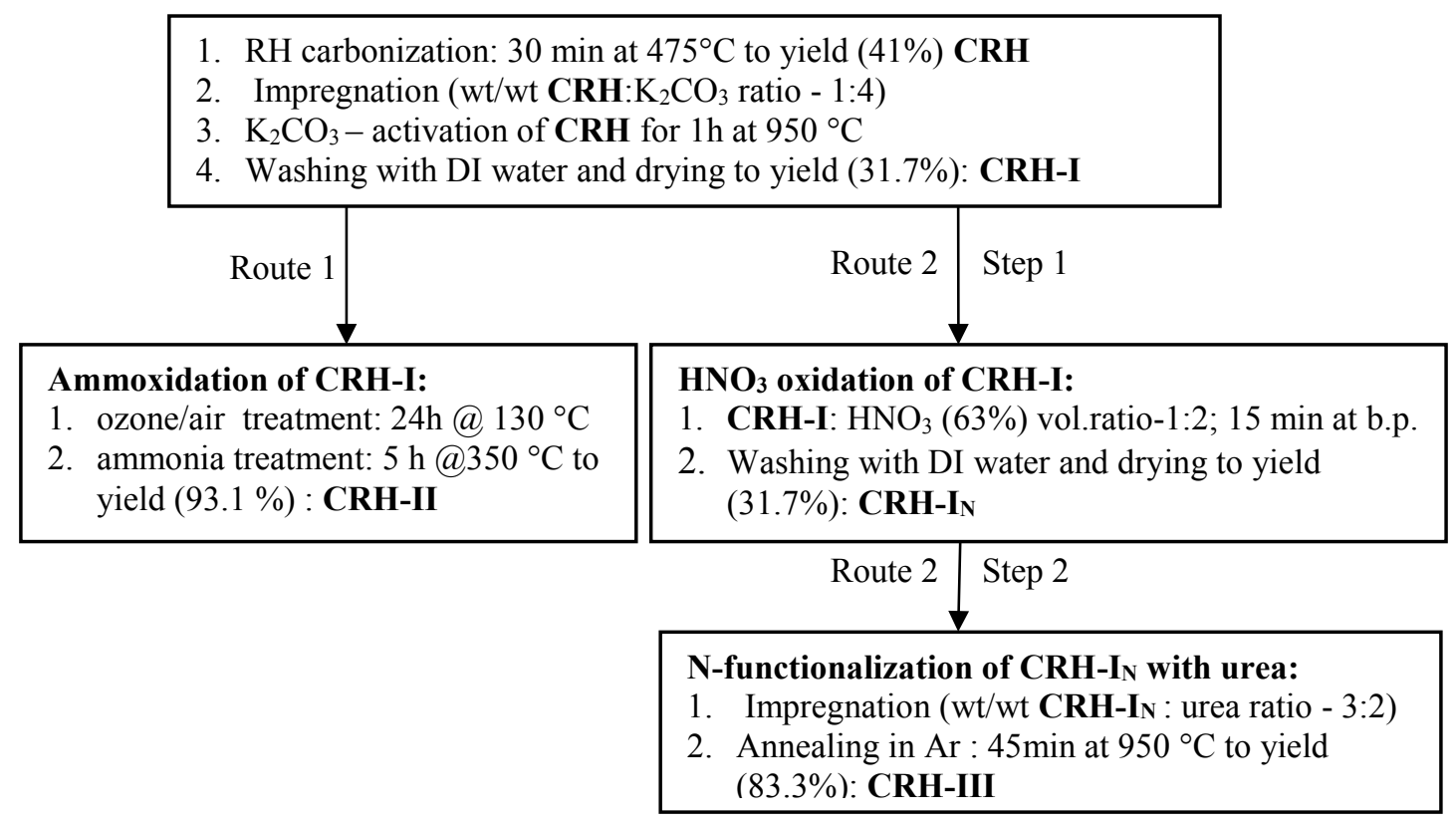

Figure 1. Block diagram of the activated carbon CRH-I modification routes.

Functionalization of activated carbon CRH-I by route 2 was carried out via oxidation with nitric acid, subsequent impregnation with urea and high-temperature treatment in inert atmosphere. Nitric acid oxidation was performed according to the procedure described elsewhere [40]; briefly, CRH-I sample was mixed with concentrated nitric acid (63 wt\%), at the ratio of $1 \mathrm{~g}$ of AC per $5 \mathrm{~mL}$ of nitric acid solution, which corresponds to $1: 2$ volume ratio) and the suspension was refluxed under mild agitation at $90{ }^{\circ} \mathrm{C}$ for 15 min. After oxidation, the samples were washed thoroughly with an excess of distilled water until neutral $\mathrm{pH}$, and dried in an oven with a yield of $96 \mathrm{wt} \%$; the resulting sample was denoted CRH-IN. In a typical procedure, $15 \mathrm{~g}$ of oxidized $\mathrm{AC}$ product $\mathrm{CRH}-\mathrm{I}_{\mathrm{N}}$ was mixed/saturated with $10 \mathrm{~g}$ of urea $(5.0 \mathrm{wt} \%$ in ethanol) at the $\mathrm{AC}$ : urea impregnation ratio of $3: 2(\mathrm{wt} / \mathrm{wt})$, then dried and annealed at $950{ }^{\circ} \mathrm{C}$ in a quartz tube reactor placed in a horizontal electric furnace under Ar flow (at the flow rate of $5 \mathrm{~L} / \mathrm{h}$ ) for $45 \mathrm{~min}$. Then sample was rapidly cooled to room temperature and the final product $\mathrm{CRH}-\mathrm{III}$ was dried in an oven at $105^{\circ} \mathrm{C}$ to constant weight of $12.5 \mathrm{~g}$, corresponding to a yield of $83.3 \mathrm{wt} \%$.

\subsection{Characterization of activated carbons 2.2.1. Textural characteristics}

The particles' surface morphology of the activated carbons was studied using field emission scanning electron microscope (FE-SEM, Zeiss Sigma) at high vacuum and $5.00 \mathrm{kV}$ EHT equipped with an energydispersive X-ray spectroscopy (EDX) detector to confirm the elemental composition of samples. The AC samples were mounted onto aluminum stubs using black carbon tapes and sputter coated with platinum (Sputter Coater Q150TES, Quorum, Italy). The Brunauer-Emmett-Teller (BET) surface area and porosity of AC were determined from $\mathrm{N}_{2}$ adsorption measurements. $\mathrm{N}_{2}$ adsorption/desorption isotherms at $77 \mathrm{~K}$ were recorded using Autosorb-1 (Quantachrome, UK) in the range of relative pressures, $p / p_{0}$, from 0.005 to 0.991 . Samples were outgassed for $10 \mathrm{~h}$ at $150{ }^{\circ} \mathrm{C}$ prior to the measurements to remove any moisture or contaminants adsorbed. The Autosorb-1 software was used to calculate BET specific surface area (S $\left.\mathrm{S}_{\mathrm{BET}}\right)$ of samples by applying the BET equation to the adsorption data. The pore volume and size distribution were calculated using the QS Density Functional Theory (QSDFT) for slit/cylindrical pores [41, 42]. The total pore volume $V_{\mathrm{T}}$ was evaluated by summation of micropore $\left(V_{\mathrm{mi}}\right)$ and mesopore $\left(V_{\mathrm{me}}\right)$ volumes. The mean 
pore diameter, $D_{\mathrm{P}}$, was calculated from equation $D_{\mathrm{P}}=4 V_{\mathrm{T}} / S_{\mathrm{BET}}$ [43]. The mercury porosimetry data were collected with a Poremaster (Quantachrome, UK) instrument.

\subsubsection{Thermal analysis}

The thermal analysis was performed using a TGA analyzer Q500 (TA Instruments) coupled with mass spectrometer (TGA-MS); measurements were carried out on $5 \mathrm{mg}$ samples at a heating rate of $10^{\circ} \mathrm{C} / \mathrm{min}$ in nitrogen atmosphere at gas flow rate of $120 \mathrm{~mL} / \mathrm{min}$; weight losses and corresponding temperatures were recorded and analyzed. Thermal decomposition data were obtained using differential scanning calorimetry (DSC, Perkin Elmer 6000 simultaneous thermal analyzer) in the heating range from 50 to $500^{\circ} \mathrm{C}$ at a heating rate of $10^{\circ} \mathrm{C} / \mathrm{min}$.

\subsubsection{X-ray photoelectron spectroscopy}

X-ray photoelectron spectroscopy (XPS) was performed using an ESCALAB 250 Xi system (Thermo Scientific) with a monochromated X-ray source of Al Ka X-rays (1486.6 eV), a hemispherical electron energy analyser, magnetic lens and video camera for viewing the analysis position. Wide scans (step size 1 $\mathrm{eV}$, pass energy $200 \mathrm{eV}$ ) and narrow scans (step size $0.1 \mathrm{eV}$, pass energy $20 \mathrm{eV}$ ) of N1s (binding energy, $\mathrm{BE}$ $\sim 399 \mathrm{eV}), \mathrm{C} 1 \mathrm{~s}(\mathrm{BE} \sim 285 \mathrm{eV}), \mathrm{O} 1 \mathrm{~s}(\mathrm{BE} \sim 531 \mathrm{eV})$, and Si 2p $(\mathrm{BE} \sim 100 \mathrm{eV})$ regions were acquired from three separate areas for each carbonaceous sample. The XPS data were transmission function corrected and analysed using Thermo Avantage Software (Version 5.952) with a smart background.

\subsubsection{Boehm titration}

Surface functionality of AC samples was assessed via modified Boehm titration procedure [44-47] using $\mathrm{pH}$ meter Orion 410A (Thermo Scientific) equipped with a Glass Combination Electrode (BDH) and a titration step of 0.1 titrant volume. In each case $0.100 \mathrm{~g}$ of activated carbon was shaken with $20 \mathrm{~mL}$ solution of $0.025 \mathrm{M} \mathrm{NaOH}$ or $0.05 \mathrm{M} \mathrm{HCl}$ in $0.1 \mathrm{M} \mathrm{NaCl}$ overnight. Then the supernatants were back-titrated with $\mathrm{HCl}$ or $\mathrm{NaOH}$, respectively, to determine the surface functionality; analysis was performed in triplicates for each sample. The total number of acidic (carboxylic, phenolic and lactone) groups was determined by their neutralization with sodium hydroxide. The number of basic sites was calculated from the amount of $\mathrm{HCl}$ required for their neutralization. The quantity of surface functional groups was expressed as milliequivalents (meq) per gram of sample.

\subsubsection{Adsorption experiments}

To analyse the adsorption capacity of the synthesised samples analytical grade sodium nitrate $\left(\mathrm{NaNO}_{3}\right.$, Sigma-Aldrich) and DI water were used to prepare stock solutions of the nitrate anion $\left(\mathrm{NO}_{3}{ }^{-}\right)$. Nitrate anion uptake was studied in batch reactor experiments at room temperature $\left(25 \pm 0.5^{\circ} \mathrm{C}\right)$. A known quantity of sample $(0.05 \mathrm{~g})$ was added to $50 \mathrm{~mL}$ aqueous solutions $(5$ or $15 \mathrm{ppm})$ and shaken continuously at $100 \mathrm{rpm}$, for $24 \mathrm{~h}$. The ion chromatography system, Dionex ICS-1100 (Thermo Fisher Scientific) was employed to determine nitrate concentration, a standard method for analysis of inorganic anions in water and wastewater [48]. Prior to the analysis all eluents were filtered through the regenerated cellulose syringe filter $(0.2 \mu \mathrm{m})$ to prevent the chromatographic column clogging. Each experiment was triplicated under identical conditions. The amount adsorbed at time $t, q_{t}(\mathrm{mg} / \mathrm{g})$, was calculated using the following equation:

$$
q_{t}=\frac{\left(C_{0-} C_{t}\right) \times V}{m}
$$

where $C_{o}$ and $C_{t}(\mathrm{mg} / \mathrm{L})$ were the initial and equilibrium $\mathrm{NO}_{3}{ }^{-}$concentrations in the aqueous solution; $V(\mathrm{~L})$ was the volume of the experimental solution and $m(\mathrm{~g})$ was the mass of dry adsorbent used.

\section{Results and Discussion}


Since higher $\mathrm{RH}$ carbonization temperature causes the reduction of yield and C-content thus increasing $\mathrm{SiO}_{2}$-content in the resulting $\mathrm{CRH}$, the temperature for $\mathrm{RH}$ carbonization most suitable for increasing the carbon content was experimentally determined at $475{ }^{\circ} \mathrm{C}$. The pyrolytic regime has an effect on the successive $\mathrm{K}_{2} \mathrm{CO}_{3}$-activation step, which comprises both processes of carbonization and desilication/activation (Equations $1.1-1.3$ ) [49].

$$
\begin{aligned}
& \mathrm{K}_{2} \mathrm{CO}_{3}+\mathrm{SiO}_{2} \rightarrow \mathrm{K}_{2} \mathrm{SiO}_{3}+\mathrm{CO}_{2} \uparrow \\
& \mathrm{CO}_{2}+\mathrm{C} \rightarrow 2 \mathrm{CO} \uparrow \\
& \mathrm{K}_{2} \mathrm{CO}_{3}+2 \mathrm{C} \rightarrow 2 \mathrm{~K}+3 \mathrm{CO} \uparrow
\end{aligned}
$$

The reactions (1.1) and (1.2) effectively start ca. $891^{\circ} \mathrm{C}$, the melting point of $\mathrm{K}_{2} \mathrm{CO}_{3}$. The evolution of gaseous $\mathrm{CO}_{2}$ and $\mathrm{CO}$ vacating the system facilitates the diffusion and soaking of the molten $\mathrm{K}_{2} \mathrm{CO}_{3}$ in the carbon matrix. Moreover, at such a high temperature $\mathrm{CO}_{2}$ is able to react with the carbon matrix causing socalled "physical" activation or "burn-off" according to the reaction (1.2). Finally, the net balance reaction (1.3) summarizes a cascade of the complex processes leading to potassium reduction and its eventual intercalation into the carbon matrix. All of these processes greatly contribute to the development of microand mesoporosity of the resulting AC.

The mechanism of nitrogen incorporation into the carbon matrix during AC surface ammoxidation via ozonolysis, hypothesized here, occurs via the Criegee mechanism of cycloaddition [50] followed by amination. According to this mechanism, formation of epoxide groups occurs in the first place with subsequent transformation of the unstable three-membered oxirane ring attacked by the strong nucleophilic molecule of ammonia resulting in creation of hydroxylic and amide groups (Fig. 2).<smiles>C=c1c(=C)c(=C)c(=C(C)C(=O)OC(C)(C)C)c(=C)c1=C</smiles><smiles></smiles><smiles>C=C1C(=O)C(C)=c2c(=C)c(=C)c(=C)c(=C)c2=C1C</smiles>

Figure 2. Scheme of the ammoxidation reaction on the AC surface.

A high temperature nitrogen functionalization of CRH-I probably involves at least five stages of nitrogen transformation over the carbonaceous surface (Fig. 3). Prior to the reaction with urea the surface of CRH-I was activated with nitric acid resulting in generation of oxygen-containing functional groups. A reaction scheme of nitrogen incorporation into the carbon matrix using high-temperature treatment of nitric acid oxidized AC impregnated with urea in order to form pyrrole/pyridine functionalities is shown in Fig. 3 (adapted from [51]).

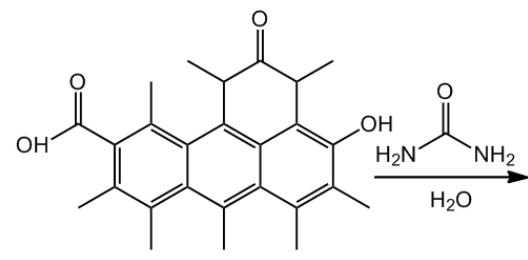<smiles>CC(=O)C1c2c(c(C)c(C)c3c(C)c(C)c(C)c(C(=O)NC(N)=O)c23)C(C)C(=O)C1C</smiles>

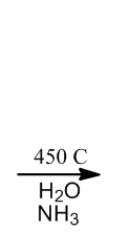

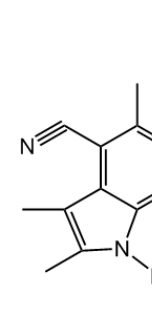

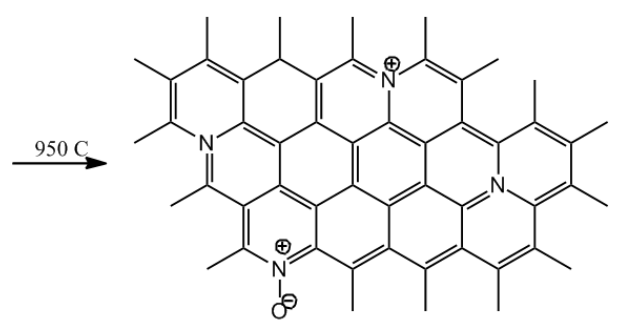



groups during the high temperature reaction with urea.

The resulting activated carbon structures strongly depend on such experimental parameters as the ratio of precursor to modifier, onset temperature of the rice husk decomposition and the temperature of final annealing. The morphology of the carbon materials obtained from rice husk was characterized by SEM (Fig. 4, a-c). The formation of distinctive plate-like structures was observed. These structural features start to appear at $950^{\circ} \mathrm{C}$ (Fig. 4, a) and remain intact following amination with ammonia (Fig. 4, b) or urea treatment (Fig. 4, c).
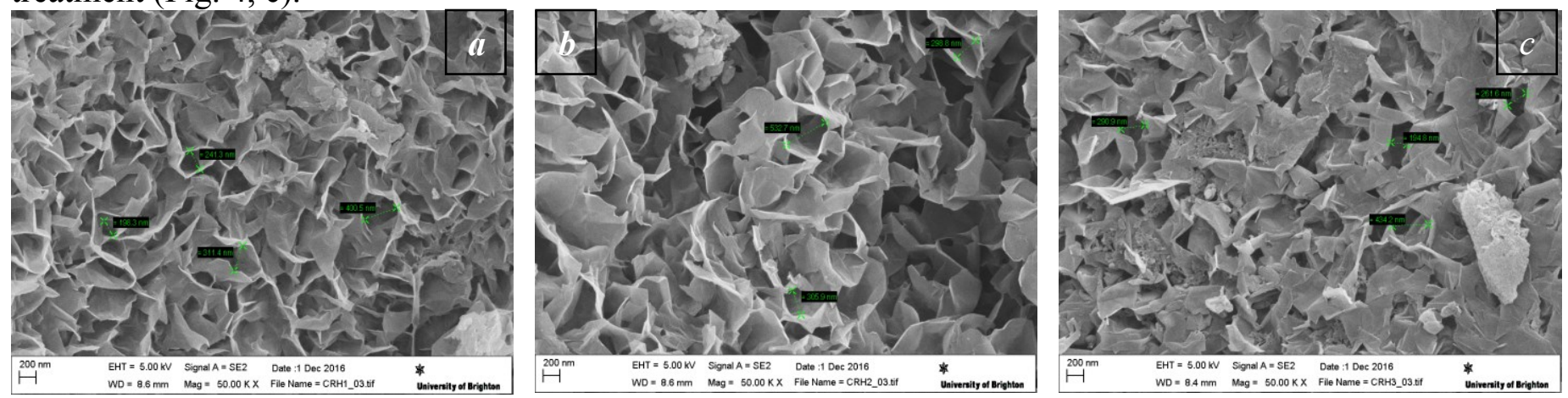

Figure 4. SEM images of activated carbon materials obtained from rice husk: CRH-I@950 (a), CRH-II (b) and CRH-III (c).

The analysis of $\mathrm{CRH}$ treated with nitric acid (CRH-III sample) shows that whilst there was no indication of structure etching or significant changes in the structure at macroscale, there was a change in the surface roughness (Fig. 4, c) and chemical functionality confirmed by XPS and SEM/EDX analysis discussed later.
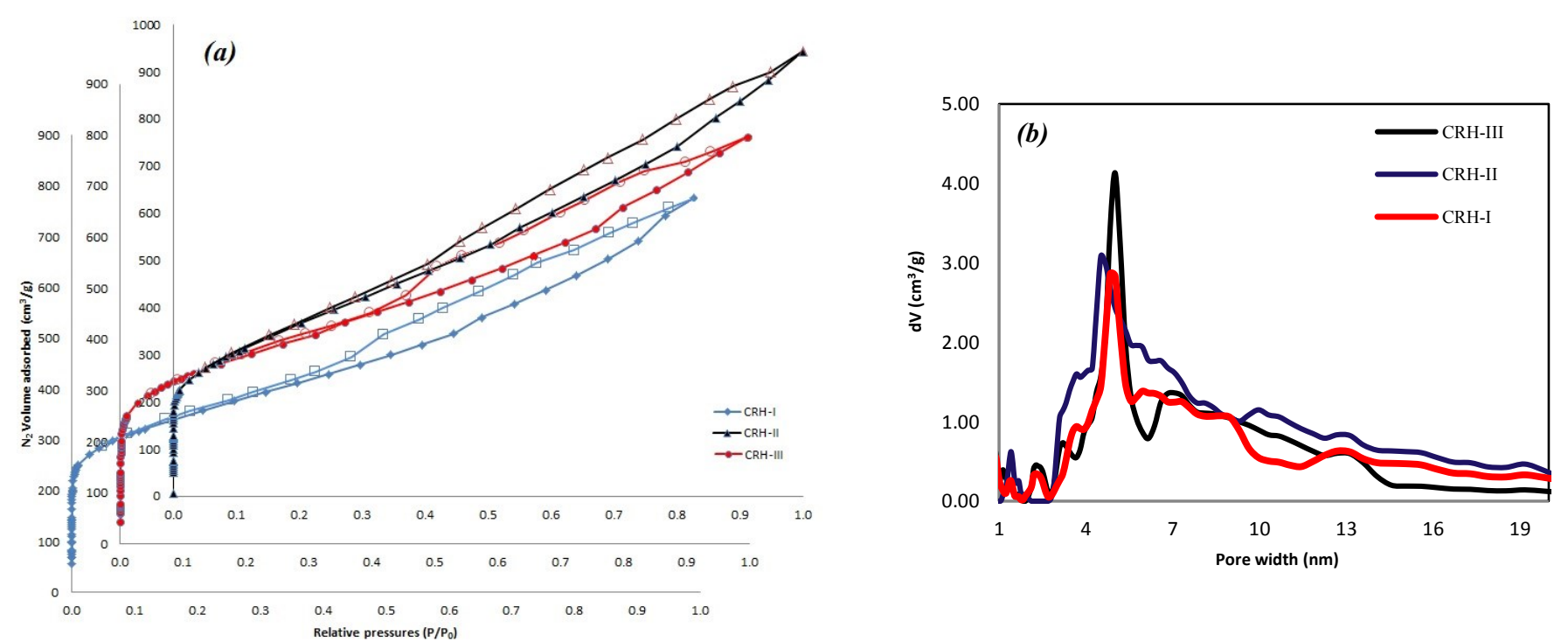

Figure 5. Low temperature nitrogen adsorption on CRH materials. Nitrogen adsorption/desorption isotherms at $77 \mathrm{~K}$ (a) and their corresponding PSDs (b).

The nitrogen adsorption/desorption isotherms at $77 \mathrm{~K}$ are shown in Fig. 5(a). All isotherms can be classified as type IV, according to IUPAC classification [52] with an uptake in the low pressure region $\left(p / p_{0} \leq 0.1\right)$ characteristic of microporous materials. However, each isotherm also shows a distinct hysteresis loop at intermediate to high relative pressures, which is characteristic of the presence of large micropores and mesopores (type IV); this is clearly shown on the graph of the pore size distribution (PSDs) in carbon samples (Fig. 5, b). A plate-like bulk with slit-like porous structure, observed by SEM (Fig. 4, a-c) is 
confirmed by $\mathbf{H 3}$ type of hysteresis loop [52] in isotherms for all three CRH samples. The observed phenomenon of a low pressure onset of the hysteresis loop in adsorption isotherms of CRH samples is often reported for carbon materials [53, 54] and commonly ascribed to intercrystalline swelling. Still, the hysteresis loop closure evidences the extent at which after given adsorption cycle the carbon returns to its original state.

The textural properties of the CRH samples shown in Table 1, as determined from the analysis of the nitrogen adsorption isotherms using BET and QSDFT methods (Fig. 5). The micropore volume, $\mathrm{V}_{\mathrm{mi}}$, corresponds to the volume adsorbed at $p / p^{0}=0.1$ and the mesopore volume, $\mathrm{V}_{\text {me, }}$ was estimated as difference between the volume of nitrogen adsorbed at $p / p^{0}=0.95$ and $p / p^{0}=0.1$. The pore size distribution was calculated by QSDFT method assuming a slit pore model [55].

Table 1. Textural properties of activated carbons.

\begin{tabular}{l|c|c|c|c|c|c|c}
\hline Sample & $\begin{array}{c}S_{\mathrm{BET}} \\
\left(\mathrm{m}^{2} / \mathrm{g}\right)\end{array}$ & $\begin{array}{c}\mathrm{S}_{\mathrm{QSDFT}} \\
\left(\mathrm{m}^{2} / \mathrm{g}\right)\end{array}$ & $\begin{array}{c}V_{\mathrm{mi}} \\
\left(\mathrm{cm}^{3} / \mathrm{g}\right)\end{array}$ & $\begin{array}{c}V_{\mathrm{me}} \\
\left(\mathrm{cm}^{3} / \mathrm{g}\right)\end{array}$ & $\begin{array}{c}V_{\mathrm{T}} \\
\left(\mathrm{cm}^{3} / \mathrm{g}\right)\end{array}$ & $\begin{array}{c}V_{\mathrm{mi}} / V_{\mathrm{T}} \\
(\%)\end{array}$ & $\begin{array}{c}D_{\mathrm{P}} \\
(\mathrm{nm})\end{array}$ \\
\hline CRH-I & 1260 & 1430 & 0.266 & 0.851 & 1.117 & 23.8 & 3.54 \\
\hline CRH-II & 1320 & 1430 & 0.257 & 0.876 & 1.133 & 22.7 & 3.44 \\
\hline CRH-III & 1330 & 1360 & 0.193 & 1.144 & 1.337 & 14.4 & 4.02 \\
\hline
\end{tabular}

As expected for this adsorption isotherm type, all samples are predominantly mesoporous and a microporous contribution to the adsorption is in the range of $\sim 14.4-23.8 \%$. The ammoxidation did not have a significant effect on the carbon porosity, and CRH-I and CRH-II samples have a very similar porous structure (Fig. 4 and Table 1). It is interesting to note that although the nitric acid oxidation has little impact on the morphology of CRH-III (Fig. 4, c), its effect on the porous structure of the activated carbon is significant. The micropore volume is reduced whereas the mesopore volume is increased, probably owing to a burn-off of micropores and converting them into mesopores. The mercury intrusion porosimetry data are presented in Fig. 6. The low pressure part of the graph (Fig. 6, a) reflects the intrusion of mercury in the interparticle space characterized by voids larger than $1 \mu \mathrm{m}$ (the right side of the graph in Fig. 6, b). The difference between samples CRH-II and CRH-III at high pressures corresponding to mercury intrusion into sub-micron pores is small but both materials show higher volume of mercury intrusion than the original sample CRH-I. These results which differ from low temperature nitrogen adsorption data suggest that subjecting samples at high pressures may lead to crushing and fracturing of pore walls, which is known for carbonaceous materials [56]. The synthetic approach described above also may lead to the formation of large macropores. Thus high pressure mercury porosimetry data show larger pores than those detected by nitrogen adsorption.
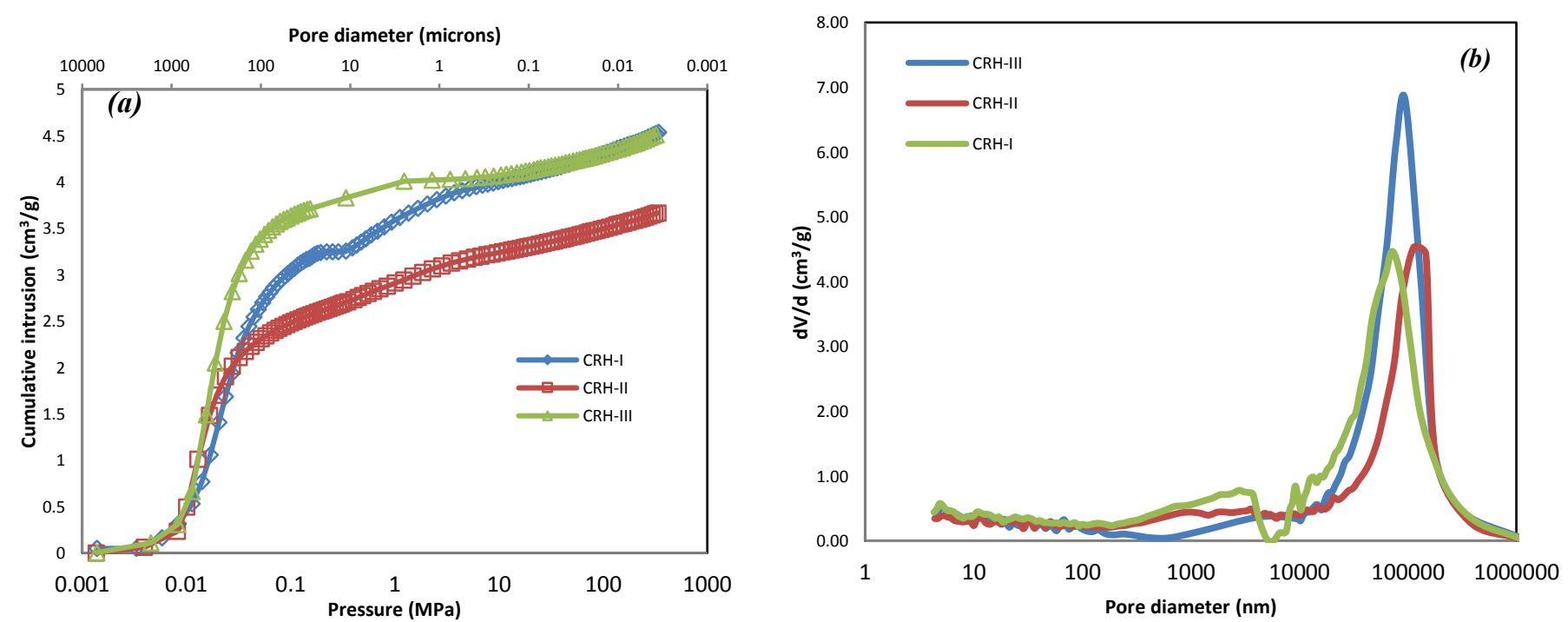

Figure 6. Mercury porosimetry intrusion data (a), and pore size distributions in CRH samples from mercury porosimetry data (b). 
The MS evolution profiles (Fig. 7, a-c) provide a record of the ion current generated by different gases or molecular fragments with different molecular mass. All profiles were plotted vs the pyrolysis temperature (Fig. 7). The present study was focused on the main volatile and combustion products evolving in the temperature range from 25 to $800{ }^{\circ} \mathrm{C}$. According to their $\mathrm{m} / \mathrm{z}$ values, some of the gaseous products can be identified as $\mathrm{H}_{2} \mathrm{O}(\mathrm{m} / \mathrm{z}=18)$, hydrocarbons such as $\mathrm{CH}_{3}{ }^{+}, \mathrm{C}_{2} \mathrm{H}_{2}{ }^{+}$and $\mathrm{C}_{2} \mathrm{H}_{6}{ }^{+}(\mathrm{m} / \mathrm{z}=15,26$ and 30 respectively); carbon oxides $\mathrm{CO}^{+}, \mathrm{CO}_{2}{ }^{++}$and $\mathrm{CO}_{2}{ }^{+}(\mathrm{m} / \mathrm{z}=28,22$ and 44 respectively) and nitrogen containing species $\mathrm{CN}^{+}(\mathrm{m} / \mathrm{z}=26)$ and $\mathrm{NCO}^{+}(\mathrm{m} / \mathrm{z}=42)$. The mass loss curves measured using TG analysis are shown in Fig. 7 (d).
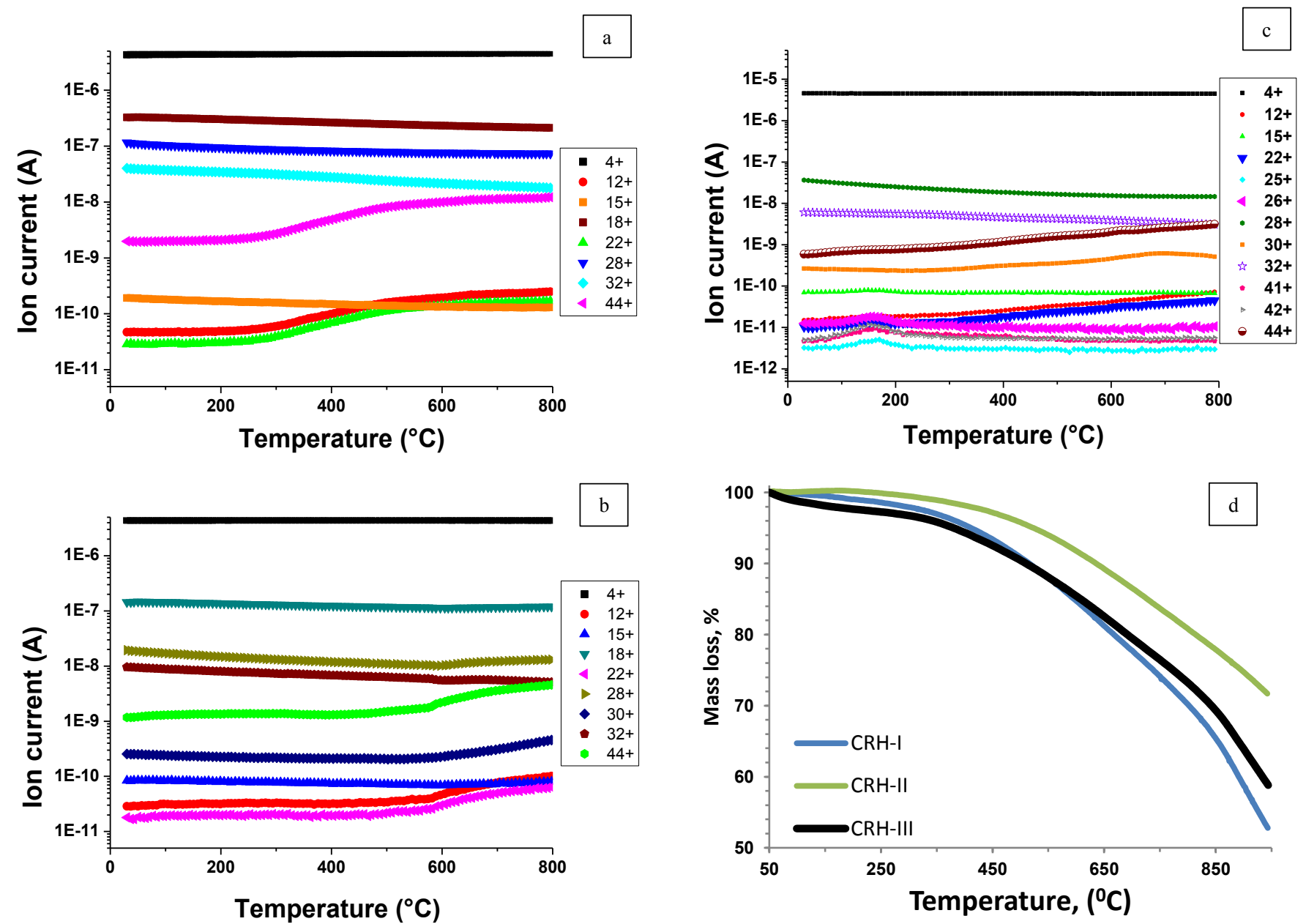

Figure 7. MS curves, an overview (y axis in logarithmic scale): CRH I (a), CRH II (b), CRH III (c) and TGA curves (d).

Fig. 7(a) shows that $\mathrm{CO}_{2}(\mathrm{~m} / \mathrm{z}: 22$ and 44) begins to evolve from CRH-I in the region between 300 and $500{ }^{\circ} \mathrm{C}$, which corresponds to the change in the mass loss slope on TGA curve (Fig. 7(d)). The evolution of carbon dioxide is caused by the destruction of oxygen-containing functional groups. MS spectrum for CRH-III sample (Fig. 7(c)) has only one peak of volatile product evolution around $160{ }^{\circ} \mathrm{C}$, together with corresponding mass loss on TGA curve (Fig. 7(d)). This mass loss is attributed to the decomposition of urea $\left(\mathrm{m} / \mathrm{z}: 22^{+}-\mathrm{CO}_{2}{ }^{++}, 26^{+}-\mathrm{CN}^{+}\right.$and $\left.42^{+}-\mathrm{NCO}^{+}\right)$, which fully decomposes at $250{ }^{\circ} \mathrm{C}$ [57]. Evolution of $\mathrm{CO}_{2}$ from CRH-II intensifies above $600{ }^{\circ} \mathrm{C}$.

XPS analysis was performed to obtain a deeper understanding of the degree of chemical modification of the CRH surface. The results of XPS survey scan analysis giving the atomic percentage of elements are presented in Table 2 and supplementary information (SI, Fig. S4). The XPS results show that CRH-III and CRH-II have a significant amount of nitrogen. The deconvolution of $\mathrm{N} 1 \mathrm{~s}$ peak revealed the presence of four different types of nitrogen-containing species N1, N2, N3 and N4 at 398.0, 399.4, 400.7 and $402.2 \mathrm{eV}$ respectively in samples CRH-II and CRH-III. These peaks could be assigned to certain types of nitrogen 
structures, such as pyridine (N1), amine/imine/amide (N2), pyrrole (N3) and quaternary nitrogen (N4) [58]. In CRH-II the N2 peak has the highest intensity, whereas in CRH-III peak N1 has the highest intensity (Fig. S4). The starting CRH-I material also has some small amount of two types of nitrogen-containing species, N1 and N3 which could be attributed to nitrogen in pyridine and pyrrole rings. The distribution of $\mathrm{N}$-containing groups in CRH-III is different from CRH-II, which was expected owing to the different synthetic routes of these two carbons. As per sample description, nitrogen was not expected in sample CRH-I. The amount of nitrogen present in CRH-I is below the detection limit of the instrument, i.e. below 0.1 atomic\%. However, a small quantity of nitrogen was detected while carrying narrow scan analysis. All samples have shown the presence of oxygen-containing functional groups and $\mathrm{Si}$, the latter originating from the raw material, rice husk. Si was not completely removed in the process of synthesis of CRH-II and CRH-III.

Table 2. Chemical composition and relative atomic ratio determined by XPS of untreated CRH-I and nitrogen-functionalised CRH-II and CRH-III activated carbons.

\begin{tabular}{c|c|c|c}
\hline Name & CRH-I & CRH-II & CRH-III \\
\hline Carbon (C) at. [\%] & $88.6 \pm 0.8$ & $90.3 \pm 0.8$ & $94.1 \pm 0.6$ \\
\hline Oxygen (O) at. [\%] & $8.8 \pm 0.4$ & $6.7 \pm 0.5$ & $3.5 \pm 0.3$ \\
\hline Silicon (Si) at. [\%] & $1.6 \pm 0.2$ & $1.1 \pm 0.2$ & $1.1 \pm 0.2$ \\
\hline Nitrogen (N) at. [\%] & $0.3 \pm 0.1$ & $1.3 \pm 0.1$ & $1.3 \pm 0.1$ \\
\hline
\end{tabular}

XPS data showed similar nitrogen content in CRH-II and CRH-III, which means that both ammoxidation and impregnation with urea introduced N-containing functional groups. The results of XPS (Table 2) and EDX analyses (Table 3) regarding the oxygen content are contradictory; according to EDX analysis, sample CRH-III has the highest oxygen content whereas XPS data suggest the opposite. The other discrepancy between the two methods is related to the silicon content. EDX analysis has found no silicon in CRH-II, whereas, according to XPS data, its content is comparable in CRH-II and CRH-III. The reason for these discrepancies is not clear, however it may be related to the difference in the chemical composition of carbons on the surface and in the bulk, since these methods probe materials to different depths. This explanation is indirectly confirmed by the fact that according to EDX analysis, no nitrogen was detected in all three samples, whereas XPS showed its presence in both samples which were obtained by surface modification with N-containing reagents, ammonia (CRH-II) and urea (CRH-III). Most likely, nitrogen containing groups are located on the uppermost surface of carbon undetectable by EDX. In EDX analysis, the content of $\mathrm{Si}$ and $\mathrm{O}$ are correlated. It possibly means that they are bound as silica which is distributed differently between the bulk and the uppermost layer of CRH samples.

The elemental composition of the carbon samples presented in Table 3, shows that all samples have a high carbon content, as expected for carbonized rice husk. The carbon content increased after ammoxidation, in agreement with the proposed reaction scheme (Fig. 2); in comparison with urea functionalization, ammoxidation completely removed silica and potassium from carbon (CRH-II). A small increase in the oxygen content from $4.6 \mathrm{wt} \%$ in CRH-I to $5.16 \mathrm{wt} \%$ in CRH-III was observed; this growth of the $\mathrm{O} / \mathrm{C}$ atom ratio in $\mathrm{CRH}-\mathrm{III}$ is related to an increase in the total amount of acidic groups created by oxidative nitric acid treatment [59].

Table 3. EDX elemental analysis of CRH-I, CRH-II and CRH-III samples.

\begin{tabular}{c|c|c|c|c}
\hline \multirow{2}{*}{ Activated carbons } & \multicolumn{4}{|c}{ Wt.\% of the elements } \\
\cline { 2 - 5 } & $\mathrm{C}$ & $\mathrm{O}$ & $\mathrm{Si}$ & $\mathrm{K}$ \\
\hline CRH-I & 93.1 & 4.6 & 1.05 & 1.03 \\
\hline CRH-II & 99.25 & 0.75 & - & - \\
\hline CRH-III & 92.3 & 5.16 & 1.45 & 1.06 \\
\hline
\end{tabular}


Table 4. Total amount of acidic/basic groups on the surface of CRH carbons and their adsorption capacity towards $\mathrm{NO}_{3}{ }^{-}$in solutions with initial concentration of 5 and $15 \mathrm{ppm}$ (mean $\mathrm{n}=3, \pm \mathrm{sd}$ ). Temperature $25^{\circ} \mathrm{C}$.

\begin{tabular}{c|c|c|c|c}
\hline Sample & Boehm acidic & Boehm basic & \multicolumn{2}{|c}{$\mathrm{NO}_{3}{ }^{-}$adsorption, $\mathrm{mg} / \mathrm{g}$} \\
\cline { 4 - 5 } & groups, meq/g & groups, meq $/ \mathrm{g}$ & $5 \mathrm{ppm}$ & $15 \mathrm{ppm}$ \\
\hline CRH-I & 1.20 & 1.65 & $0.87 \pm 0.053$ & $3.76 \pm 0.047$ \\
\hline CRH-II & 1.36 & 1.90 & $0.90 \pm 0.036$ & $3.80 \pm 0.033$ \\
\hline CRH-III & 0.90 & 3.40 & $2.20 \pm 0.032$ & $8.11 \pm 0.031$ \\
\hline
\end{tabular}

Nitrate adsorption from aqueous solutions by samples CRH-I and CRH-II is lower than that of CRHIII (Table 4) and similar to other activated carbon materials [60]. The adsorption effectiveness of CRH-III for nitrate was two times higher in the concentration range of 5-15 ppm studied in this work. A relatively minor difference in the textural properties of activated carbons (Table 1) could not have such a strong effect on the nitrate adsorption capacity of CRH-III. The results of acid-base titration (Table 4) suggest that urea modification added more positively charged basic functional groups which according to XPS data could be assigned to the pyridine-like nitrogen state (Fig. 3). Based on the acid-base titration data a schematic of the interaction of nitrate ion with surface of CRH-III is proposed (Fig. 8). Since the ammonolysis of CRH-I did not lead to an increased content of basic groups in CRH-II, it is likely that the dominant nitrogen species in $\mathrm{CRH}-\mathrm{II}$ is likely to be an amide-like state rather than amine-like state, the former having weak basic properties.
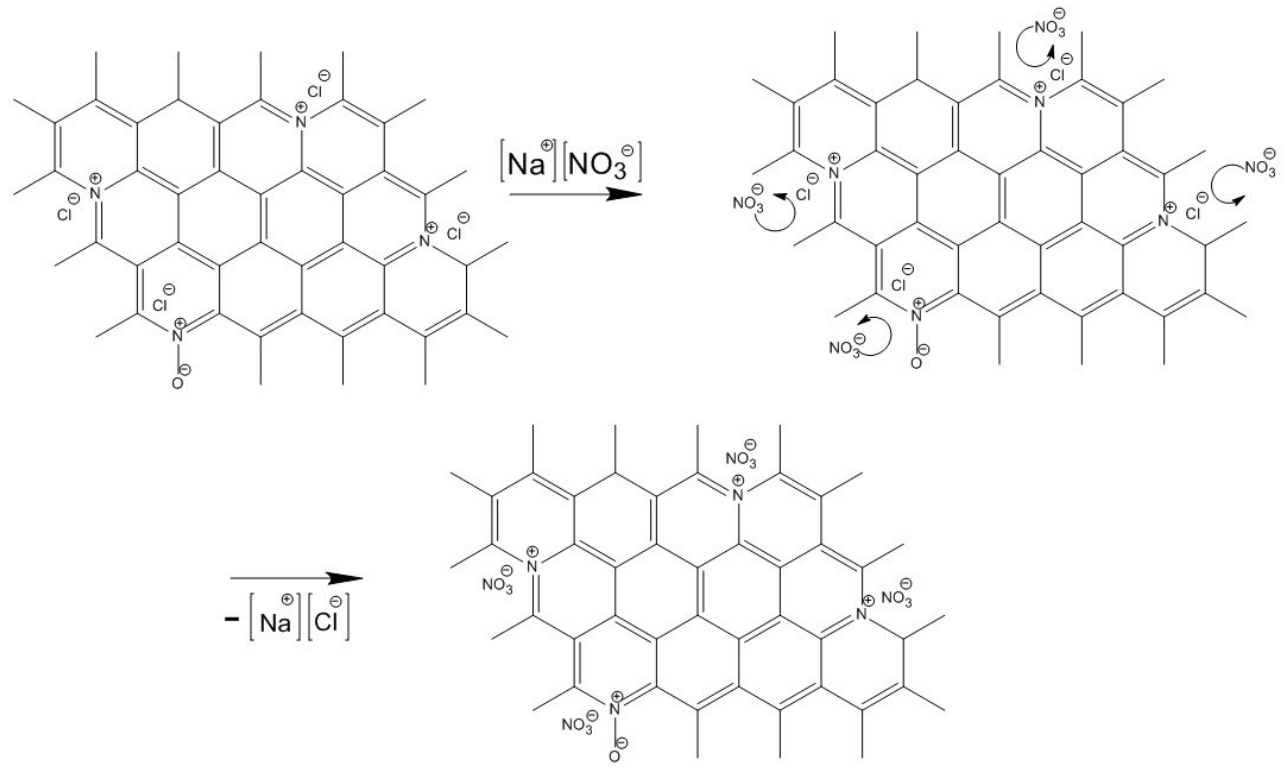

Figure 8. Proposed mechanism of nitrate ion removal by CRH-III as ion exchange.

The results presented show the impact of the activated carbon surface functionality on nitrate adsorption. Particularly, basic nitrogen containing groups on the surface introduced by modification with urea could act as adsorption sites for nitrate ions enhancing the adsorption capacity of CRH-III carbon towards nitrate.

\section{Conclusions and future perspectives}


Effective porous carbons for removal of nitrate anions from aqueous solutions have been developed by chemical activation of carbonized rice husk using potassium carbonate as activating and desilicating agent, and further post-treated by gas phase ammoxidation with ozone/ammonia or oxidation with concentrated nitric acid followed by nitrification with urea. It has been demonstrated that introducing basic nitrogencontaining groups in the pyridine-like state into carbonized rice husk enhanced anion exchange properties of activated carbon CRH-III which correlated with enhanced nitrate adsorption. Introduction of nitrogencontaining groups in the amine/amide-like state via low-temperature treatment (CRH-II) did not alter its adsorption capacity towards nitrate compared to the initial sample (CRH-I). As revealed from literature, only a few agricultural wastes have been investigated for nitrate removal and urea modified carbonized rice husk shows an appreciable potential for denitrification (Supplementary Table S1). Thus, it would be worth to investigate a more wide range of nitrate concentrations and effectiveness in a presence of adsorptive competing ions in real industrial effluents.

\section{ACKNOWLEDGMENTS}

Authors express their gratitude to Prof Krisztina Laszlo, Budapest University of Technology and Economics, Hungary, for TGA-MS experiments and discussion and to Dr Santanu Ray, University of Brighton, UK, for XPS measurements and discussion.

This work has been financially supported by Nazarbayev University (project ORAU "HyperActiv"), Kazakhstan, European Commission, Horizon 2020 MSCA-RISE-2016 project 'NanoMed', and the Royal Academy of Engineering (UK), projects IAPP/1516/46 and IAPP/1516/3.

\section{References}

1. Arauzo, M., Vulnerability of groundwater resources to nitrate pollution: A simple and effective procedure for delimiting Nitrate Vulnerable Zones. Science of The Total Environment, 2017. 575: p. 799-812.

2. Tournebize, J., C. Chaumont, and Ü. Mander, Implications for constructed wetlands to mitigate nitrate and pesticide pollution in agricultural drained watersheds. Ecological Engineering, 2017. 103: p. 415-425.

3. Fewtrell, L., Drinking-Water Nitrate, Methemoglobinemia, and Global Burden of Disease: A Discussion. Environmental Health Perspectives, 2004. 112(14): p. 1371-1374.

4. Shuval, H.I. and N. Gruener, Infant methemoglobinemia and other health effects of nitrates in drinking water. Prog. Wat. Tech. Vol., 1977. 8(4-5): p. 183-193.

5. Sadeq, M., et al., Drinking water nitrate and prevalence of methemoglobinemia among infants and children aged 1-7 years in Moroccan areas. International Journal of Hygiene and Environmental Health, 2008. 211(56): p. 546-554.

6. Brender, J.D., et al., Prenatal nitrate intake from drinking water and selected birth defects in offspring of participants in the National Birth Defects Prevention Study. Environmental Health Perspectives 2013. 121(9): p. 1083-1089.

7. EPA., U.S., Estimated National Occurrence and Exposure to Nitrate/Nitrite in Public Drinking Water Supplies. 1990, Environmental Protection Agency: Washington, DC: U.S. p. 2-32.

8. EPA, U.S., Drinking Water from Household Wells. EPA 816-K-02-003. 2002, Environmental Protection Agency: Washington, DC: U.S. p. 1-24.

9. Health hazards from nitrate in drinking-water. Report on a WHO meeting Copenhagen, 5-9 March 1984., in Environmental Health Series. 1985, WHO Regional Office for Europe: Copenhagen, Denmark. p. 1-112.

10. Hudak, P.F., Regional trends in nitrate content of Texas groundwater. Journal of Hydrology, 2000. 228(1-2): p. 37-47.

11. Wilkinson, G.M., Eutrophication of Freshwater and Coastal Ecosystems A2 - Abraham, Martin A, in Encyclopedia of Sustainable Technologies. 2017, Elsevier: Oxford. p. 145-152.

12. Wick, K., C. Heumesser, and E. Schmid, Groundwater nitrate contamination: Factors and indicators. Journal of Environmental Management, 2012. 111: p. 178-186.

13. Li, R., et al., Nitrate removal efficiency of a mixotrophic denitrification wall for nitrate-polluted groundwater in situ remediation. Ecological Engineering, 2017. 106: p. 523-531.

14. Samatya, S., et al., Removal of nitrate from aqueous solution by nitrate selective ion exchange resins. Reactive and Functional Polymers, 2006. 66(11): p. 1206-1214. 
15. Chabani, M., A. Amrane, and A. Bensmaili, Kinetic modelling of the adsorption of nitrates by ion exchange resin. Chemical Engineering Journal, 2006. 125(2): p. 111-117.

16. Wang, G., et al., Hierarchical porous carbon derived from rice husk as a low-cost counter electrode of dyesensitized solar cells. Renewable Energy, 2014. 63: p. 708-714.

17. Demiral, H. and G. Gündüzoğlu, Removal of nitrate from aqueous solutions by activated carbon prepared from sugar beet bagasse. Bioresource Technology, 2010. 101(6): p. 1675-1680.

18. Olivares-Marín, M., et al., Preparation of activated carbons from cherry stones by activation with potassium hydroxide. Applied Surface Science, 2006. 252(17): p. 5980-5983.

19. Stavropoulos, G.G. and A.A. Zabaniotou, Production and characterization of activated carbons from oliveseed waste residue. Microporous and Mesoporous Materials, 2005. 82(1-2): p. 79-85.

20. Azevedo, D.C.S., et al., Microporous activated carbon prepared from coconut shells using chemical activation with zinc chloride. Microporous and Mesoporous Materials, 2007. 100(1-3): p. 361-364.

21. Chang, C.-F., C.-Y. Chang, and W.-T. Tsai, Effects of Burn-off and Activation Temperature on Preparation of Activated Carbon from Corn Cob Agrowaste by CO2 and Steam. Journal of Colloid and Interface Science, 2000. 232(1): p. 45-49.

22. Demiral, H., et al., Production of activated carbon from olive bagasse by physical activation. Chemical Engineering Research and Design, 2011. 89(2): p. 206-213.

23. Daud, W.M.A.W. and W.S.W. Ali, Comparison on pore development of activated carbon produced from palm shell and coconut shell. Bioresource Technology, 2004. 93(1): p. 63-69.

24. Nunell, G.V., et al., Conversion of biomass from an invasive species into activated carbons for removal of nitrate from wastewater. Biomass and Bioenergy, 2012. 44: p. 87-95.

25. Liu, Y., et al., A sustainable route for the preparation of activated carbon and silica from rice husk ash. Journal of Hazardous Materials, 2011. 186(2): p. 1314-1319.

26. Shen, Y., P. Zhao, and Q. Shao, Porous silica and carbon derived materials from rice husk pyrolysis char. Microporous and Mesoporous Materials, 2014. 188: p. 46-76.

27. Alvarez, J., et al., Upgrading the rice husk char obtained by flash pyrolysis for the production of amorphous silica and high quality activated carbon. Bioresource Technology, 2014. 170: p. 132-137.

28. Liu, D., et al., A green technology for the preparation of high capacitance rice husk-based activated carbon. Journal of Cleaner Production, 2016. 112: p. 1190-1198.

29. Guo, Y., et al., The preparation and mechanism studies of rice husk based porous carbon. Materials Chemistry and Physics, 2002. 74(3): p. 320-323.

30. Liou, T.-H. and S.-J. Wu, Characteristics of microporous/mesoporous carbons prepared from rice husk under base- and acid-treated conditions. Journal of Hazardous Materials, 2009. 171(1): p. 693-703.

31. Xiao, Y., et al., Porous carbon with ultrahigh specific surface area derived from biomass rice hull. Materials Letters, 2014. 116: p. 185-187.

32. Guo, Y., et al., Performance of electrical double layer capacitors with porous carbons derived from rice husk. Materials Chemistry and Physics, 2003. 80(3): p. 704-709.

33. Li, D., et al., Preparation of porous carbons with high low-pressure CO2 uptake by KOH activation of rice husk char. Fuel, 2015. 139: p. 68-70.

34. Nunell, G.V., et al., Nitrate uptake improvement by modified activated carbons developed from two species of pine cones. Journal of Colloid and Interface Science, 2015. 440: p. 102-108.

35. Dempster, D.N., D.L. Jones, and D.V. Murphy, Clay and biochar amendments decreased inorganic but not dissolved organic nitrogen leaching in soil. Soil Research, 2012. 50(3): p. 216-221.

36. Kameyama, K., et al., Influence of Sugarcane Bagasse-derived Biochar Application on Nitrate Leaching in Calcaric Dark Red Soil. Vol. 41. 2012. 1131-7.

37. World Rice Production 2016/2017. 2017 May 2017; Available from: https:/www.worldriceproduction.com/.

38. J.M. Jandosov, et al., Mesoporous Composite Materials from Acivated Rice husk Carbon and Montmorillonite Eurasian Chemico-Technological Journal, 2011. 13(1-2): p. 105-113.

39. Liu, Y., et al., Simultaneous preparation of silica and activated carbon from rice husk ash. Journal of Cleaner Production, 2012. 32: p. 204-209.

40. Ania, C.O., J.B. Parra, and J.J. Pis, Influence of oxygen-containing functional groups on active carbon adsorption of selected organic compounds. Fuel Processing Technology, 2002. 79(3): p. 265-271.

41. Gregg, S.J. and K.S.W. Sing, Adsorption, Surface Area and Porosity. 2nd ed. 1982, London: Academic press inc. LTD.

42. Thommes, M., Physical Adsorption Characterization of Nanoporous Materials. Chemie Ingenieur Technik, 2010. 82(7): p. 1059-1073. 
43. Díaz-Díez, M.A., et al., Porous texture of activated carbons prepared by phosphoric acid activation of woods. Applied Surface Science, 2004. 238(1-4): p. 309-313.

44. Boehm, H.P., Surface oxides on carbon and their analysis: a critical assessment. Carbon, 2002. 40(2): p. $145-$ 149.

45. Goertzen, S.L., et al., Standardization of the Boehm titration. Part I. CO2 expulsion and endpoint determination. Carbon, 2010. 48(4): p. 1252-1261.

46. Oickle, A.M., et al., Standardization of the Boehm titration: Part II. Method of agitation, effect of filtering and dilute titrant. Carbon, 2010. 48(12): p. 3313-3322.

47. Hulicova-Jurcakova, D., et al., Combined Effect of Nitrogen- and Oxygen-Containing Functional Groups of Microporous Activated Carbon on its Electrochemical Performance in Supercapacitors. Advanced Functional Materials, 2009. 19(3): p. 438-447.

48. Determination of Anions by Ion Chromatography, in Methods for IC with chemical suppression of eluent conductivity (4110B). 2000, The Standard Methods Organization: https://www.standardmethods.org/store/ProductView.cfm?ProductID=31.

49. Yonghui $\mathrm{Hu}$, et al., Preparation of Chitosan-Based Activated Carbon and Its Electrochemical Performance for EDLC. Journal of the Electrochemical Society, 2013. 160(6): p. H321-H326.

50. Simmons, J.M., et al., Effect of Ozone Oxidation on Single-Walled Carbon Nanotubes. The Journal of Physical Chemistry B, 2006. 110(14): p. 7113-7118.

51. Seredych, M., et al., Surface functional groups of carbons and the effects of their chemical character, density and accessibility to ions on electrochemical performance. Carbon, 2008. 46(11): p. 1475-1488.

52. Sing, K.S.W., Reporting physisorption data for gas/solid systems with special reference to the determination of surface area and porosity (Recommendations 1984). Pure and Applied Chemistry, 1985. 57(4): p. 603-619.

53. McDermot, H.L. and B.E. Lawton, The adsorption of nitrogen by carbon black and graphite. Canadian Journal of Chemistry, 1956. 34(6): p. 769-774.

54. McDermot, H.L. and J.C. Arnell, The adsorption of nitrogen, oxygen, and argon by graphite. Canadian Journal of Chemistry, 1955. 33(5): p. 913-922.

55. Evans, R., U.M.B. Marconi, and P. Tarazona, Capillary condensation and adsorption in cylindrical and slitlike pores. Journal of the Chemical Society, Faraday Transactions 2: Molecular and Chemical Physics, 1986. 82(10): p. 1763-1787.

56. Dickinson, J.M. and J.W. Shore, Observations concerning the determination of porosities in graphites. Carbon, 1968. 6(6): p. 937-941.

57. Schaber, P.M., et al., Thermal decomposition (pyrolysis) of urea in an open reaction vessel. Thermochimica Acta, 2004. 424(1): p. 131-142.

58. Yang, G., et al., Amination of activated carbon for enhancing phenol adsorption: Effect of nitrogencontaining functional groups. Applied Surface Science, 2014. 293: p. 299-305.

59. Soudani, N., S. Souissi-najar, and A. Ouederni, Influence of Nitric Acid Concentration on Characteristics of Olive Stone Based Activated Carbon. Chinese Journal of Chemical Engineering, 2013. 21(12): p. 1425-1430.

60. Mizuta, K., et al., Removal of nitrate-nitrogen from drinking water using bamboo powder charcoal. Bioresource Technology, 2004. 95(3): p. 255-257. 